\title{
Cotidiano de portadores de esquizofrenia após uso de clozapina e acompanhamento grupal
}

\author{
DAILY LIFE OF SCHIZOFRENIA PATIENTS AFTER THE USE OF CLOZAPINE \\ AND GROUP FOLLOW UP
EL COTIDIANO DE PORTADORES DE ESQUIZOFRENIA DESPUÉS DEL USO DE CLOZAPINAY ACOMPAÑAMIENTO DEL GRUPO

\section{Ana Maria Sertori Durão1, Maria Conceição Bernardo de Mello e Souza², Adriana Inocenti Miasso}

\section{RESUMO}

Este estudo descreve a visão do portador de esquizofrenia sobre seu cotidiano após o uso da clozapina e acompanhamento em grupo. A amostra foi constituída por 11 pacientes que participam do grupo de medicações atípicas (GRUMA) do Hospital das Clínicas da Faculdade de Medicina de Ribeirão Preto-USP. Para coleta de dados, utilizou-se uma entrevista semiestruturada, guiada por um roteiro, em abril de 2003. As entrevistas foram gravadas e, posteriormente, transcritas na íntegra. Obteve-se, como resultados, melhora do paciente quanto aos sintomas da doença, evidenciada pela diminuição do isolamento social, retomada das atividades domésticas/trabalho, estudo e participação em atividades de convívio social. Tais resultados apontam para a necessidade de um novo olhar dirigido ao portador de transtorno mental, no sentido de buscar atitudes terapêuticas adequadas, que atuem na produção de vida, visando a um novo sentido para a existência, nas diferentes formas de convivência e de sociabilidade.

\section{DESCRITORES}

Esquizofrenia.

Clozapina.

Psicoterapia de grupo.

Resultado de tratamento.

\section{ABSTRACT}

This study was carried out with a sample of 11 patients who are part of the atypical medication group at the Hospital das Clínicas of the University of São Paulo at Ribeirão Preto's School of Medicine. For data collection semi-structured interviews guided by a script were held in April 2003. The interviews were first taped and fully transcribed afterwards. Results indicated an improvement in patients' symptoms, demonstrated by decreased social isolation, resumption of home/work activities and studies, as well as by participation in social events. They also point out to the need for a new vision regarding patients who suffer from mental disorders and their family members in the sense of searching for adequate therapeutic attitudes that have an impact on the production of life, aimed at giving a new existential meaning in the different forms of social contact and sociability.

\section{KEY WORDS}

Schizophrenia.

Clozapine.

Psychotherapy group.

Treatment outcome.

\section{RESUMEN}

Este estudio describió el punto de vista de los portadores de esquizofrenia en su cotidiano después del uso de clozapina y acompañamiento en grupo. La muestra fue constituida por 11 portadores de esquizofrenia que participaron del grupo de medicación clozapina del Hospital das Clínicas de Ribeirao Preto/USP. Para la colección de datos se utilizó una entrevista orientada por guión, en abril de 2003. Las entrevistas fueron registradas y después transcritas por entero. Los resultados indicaron la mejoría de los pacientes con respecto a los síntomas de la enfermedad, evidenciada por la disminución del aislamiento social, recomienzo de actividades domésticas/trabajo, estudio y participación en actividades de convivencia social. Tales resultados señalan la necesidad de una nueva manera de mirar el portador de trastorno mental y sus familiares en el sentido de buscar actitudes terapéuticas que actúen en la producción de vida, en un nuevo sentido para la existencia, en las diferentes formas de convivencia y de sociabilidad.
1 Enfermeira do Hospital das Clínicas - Faculdade de Medicina de Ribeirão Preto-USP.

Professora do Centro Universitário Barão

de Mauá. Mestranda

da Escola de

Enfermagem de

Ribeirão Preto-USP.

2 Enfermeira

Professora Doutora do Departamento de

Enfermagem

Psiquiátrica e

Ciências Humanas

da Escola de

Enfermagem de

Ribeirão Preto-USP

3 Enfermeira.

Professora do

Departamento de

Enfermagem

Psiquiátrica e

Ciências Humanas

da Escola de

Enfermagem de

Ribeirão Preto-USP.

Doutoranda do

Programa

Interunidades de

Enfermagem da EE-

EERP-USP.

amiasso@ eerp.usp.br 


\section{INTRODUÇÃO}

A esquizofrenia é um transtorno do pensamento que se caracteriza por uma desorganização de diversos processos mentais, sendo uma das desordens psiquiátricas mais desafiadoras e complexas que afligem a humanidade levando o indivíduo a apresentar vários sintomas ${ }^{(1)}$.

Desse modo, a esquizofrenia é um problema grave e, segundo as estatísticas, atinge $1 \%$ da população sem distinção de sexo, raça ou classe social. Na maioria dos pacientes, aparece em idade precoce, entre 15 a 54 anos de idade. Constituise uma doença de origem desconhecida e, isso, leva a existência de controvérsias em relação as suas causas ${ }^{(2-3)}$.

Atualmente, os sintomas que podem ser observados na esquizofrenia vêm sendo agrupados em sintomas: positivos (delírios, alucinações, desorganização do pensamento), negativos (diminuição da vontade e da afetividade, o empobrecimento do pensamento e o isolamento social), cognitivos (dificuldade na atenção, concentração, compreensão e abstração) e afetivos (a depressão, a desesperança, idéias de tristeza, ruína $\mathrm{e}$, inclusive, autodestrutivas) $)^{(3)}$.

Para que a pessoa receba o diagnóstico de esquizofrenia, é necessário apresentar os sintomas característicos dessa patologia de modo contínuo, por um tempo mínimo de 6 meses, devendo, ainda, estar funcionando abaixo do seu nível mais alto alcançado anteriormente ${ }^{(4)}$.

Assim, constitui-se uma doença crônica, que necessita de acompanhamento por tempo indeterminado, com objetivo de identificar os aspectos evolutivos da doença e a prevenção de recaídas, pois quanto menos recaídas, menor será seu comprometimento ${ }^{(3)}$.

Na década de 50, a utilização de drogas antipsicóticas pode ser considerada como um passo inicial para a desinstitucionalização e o cuidado do indivíduo na própria comunidade. Comprovadamente, o tratamento medicamentoso melhora os sintomas psicóticos, diminuindo a suscetibilidade da recorrência, mantendo a estabilidade clínica e, possivelmente, previnindo a deteriorização em longo prazo.

A clozapina é um antipsicótico atípico que está sendo usado para o tratamento da esquizofrenia desde a década de 70 do século passado. $\mathrm{O}$ seu perfil terapêutico foi sendo confirmado gradativamente através de diversos estudos. Na Finlândia em 1975 foram observados dezesseis casos de agranulocitose entre pacientes tratados com clozapina, dos quais oito foram fatais. Em decorrência disso, o medicamento passou a ser prescrito sob critérios rigorosos, fazendo-se acompanhamento dos pacientes com monitorização hematológica freqüente ${ }^{(5)}$.
As suas vantagens terapêuticas em relação aos neurolépticos convencionais são caracterizadas por amplo espectro de atividade antipsicótica, rapidez de início de ação e ausência relativa de reações extrapiramidais. Pacientes esquizofrênicos resistentes a outros neurolépticos, apresentam melhora tanto dos sintomas positivos como dos sintomas negativos ${ }^{(6)}$. A clozapina começou a ser testada em estudos abertos a partir de 1970 e foi lançada comercialmente em agosto de $1992^{(7)}$

A agranulocitose é o mais grave efeito adverso desse medicamento, sendo observada em 1 a $2 \%$ dos casos. A diminuição dos leucócitos totais, granulócitos e neutrófilos é, geralmente, gradual sendo obrigatório interromper-se o tratamento se eles atingirem níveis inferiores a 3000/ $\mathrm{mm}^{3} \mathrm{e}$ $1500 \mathrm{~mm}^{3}$, respectivamente. Entretanto, há casos em que a redução é abrupta, justificando-se a monitorização semanal, pelos menos no período de risco máximo ${ }^{(5)}$.

Desse modo, para que essa medicação possa ser utilizada com segurança, a equipe de saúde, familiares e pacientes devem estar atentos quanto aos resultados dos exames hematológicos, e a quaisquer sinais ou sintomas de infecção.

Embora o uso de psicofármacos seja indispensável ao controle dos sintomas psicóticos da esquizofrenia, sabe-se que a utilização de estratégias que combinam medicação e tratamento psicossocial aumenta a possibilidade de recuperação e podem otimizar os resultados. Várias são as possibilidades de intervenções psicossociais, dentre elas destacam-se as psicoterapias cujos objetivos podem ser alcançados através de intervenções grupais, individuais e/ ou com familiares Dependendo dos seus objetivos e do contexto em quem se insere, a atividade grupal pode promover educação, suporte, desenvolvimento emocional e treinamento das atividades sociais e vocacionais ${ }^{(8)}$.

A psicoterapia de grupo é a aplicação das técnicas psicoterápicas a um grupo de pacientes no qual, tanto as interações paciente-paciente, quanto às interações paciente-terapeuta são usadas para efetuar mudanças no comportamento mal adaptado de cada um dos membros do grupo $^{(9)}$.

Em relação à classificação geral dos grupos, esta se fundamenta nos critérios das finalidades a que se destina o grupo, onde existem dois grandes ramos: operativos e psicoterápicos. Os operativos são um continente de todos os demais grupos, inclusive os terapêuticos, e envolvem, quatro campos: ensino-aprendizagem, institucionais, comunitários e terapêuticos. Os grupos psicoterápicos são estritamente para aquelas formas de psicoterapia que se destinam prioritariamente à aquisição de insight, notadamente, 
dos aspectos inconscientes dos indivíduos e da totalidade grupal. Algumas formas de grupoterapias merecem um registro: psicodramática, teoria sitêmica, cognitiva, comportamental e psicanalítica ${ }^{(10)}$.

Os trabalhos em grupos têm grande relevância e são tão efetivos quanto à psicoterapia individual no tratamento de vários transtornos psicológicos ${ }^{(9)}$.

O trabalho em grupo, facilita o processo educativo, que tem a finalidade de transmitir informações para a população, objetivando a conscientização a respeito dos agravos à saúde. No entanto, isto só irá acontecer se a pessoa que receber a informação ver isto como importante para $\mathrm{si}^{(11)}$.

Tendo em vista esses aspectos a equipe de saúde da unidade de psiquiatria do Hospital das Clínicas da Faculdade de Medicina de Ribeirão Preto-USP, criou o GRUMA (Grupo De Medicações Atípicas). Este, funciona desde 1999 no $3^{\circ}$ andar (unidade "C") do referido hospital. Surgiu da necessidade de formalizar o atendimento ao grupo de pacientes em uso de clozapina e seus familiares. São pacientes com indicação para o GRUMA aqueles com diagnóstico de esquizofrenia, que obtiveram melhor controle de sua doença com o uso dos antipsicóticos atípicos (clozapina, olanzapina, quetiapina, risperidona).

Constituem objetivos do GRUMA: reavaliação psiquiátrica periódica, com solicitação de hemograma e outros exames; controle dos processos de aquisição gratuita de novos antipsicóticos (medicações de alto custo) e reintegração social através da troca de informações; envolvimento familiar no tratamento e estimulo à participação em atividades comunitárias.

Os encontros grupais são realizados às segundas-feira, das 14 às 15 horas, envolvendo pacientes e seus familiares. A equipe responsável pelo atendimento do grupo é composta por uma enfermeira, uma assistente social, uma aprimoranda do serviço social, um médico assistente e um médico residente $\left(R_{2}\right)$.

Considera-se de extrema importância dirigir o olhar ao portador de esquizofrenia a fim de absorver suas inquietações, satisfações, críticas em relação à terapêutica oferecida. Acredita-se que um trabalho dessa natureza poderá contribuir para discussões com a equipe de saúde envolvida no tratamento, buscando um aprimoramento na assistência prestada ao portador de esquizofrenia e seu familiar.

\section{OBJETIVO}

Avaliar a visão do portador de esquizofrenia sobre seu cotidiano após o uso da clozapina e acompanhamento em grupo.

\section{MÉTODO}

\section{Delineamento do estudo}

Trata-se de uma pesquisa de avaliação que tem como propósito "descobrir quão bem está funcionando um programa, tratamento, prática ou política”. Na pesquisa de avaliação o que se quer é encontrar respostas a questões práticas, colocadas pelas pessoas que precisam tomar decisões. Desse modo, tem o propósito detectar o quanto um procedimento esta funcionando ${ }^{(12)}$. Para o desenvolvimento da investigação optamos por trabalhar com dados qualitativos.

\section{Sujeitos do estudo}

A amostra foi constituída por 11 portadores de esquizofrenia que utilizam clozapina e participam do grupo de medicações atípicas (GRUMA) do Hospital das Clínicas da Faculdade de Medicina de Ribeirão Preto/ USP.

\section{Coleta de dados}

Os dados foram coletados após a aprovação do projeto pelo Comitê de Ética de Pesquisa em Seres Humanos da instituição hospitalar em estudo, conforme Resolução 196/96 $6^{(13)}$.

Para coleta de dados utilizou-se a técnica de entrevista guiada por um roteiro semi-estruturado. As entrevistas foram realizadas no mês de abril de 2003, com data e horário pré-estabelecidos, no "Posto C" localizado no $3^{\circ}$ andar do Hospital das Clínicas da Faculdade de Medicina de Ribeirão Preto da Universidade de São Paulo (HCFMRP-USP), local onde acontecem os grupos. As entrevistas foram gravadas e, posteriormente, transcritas na íntegra pelo próprio pesquisador. Foram numeradas de um a onze, na ordem em que foram acontecendo. Assim, os sujeitos estão identificados por números, de um a onze, com a finalidade de garantir o anonimato e o sigilo das informações. Foi solicitado o consentimento livre e informado aos participantes do estudo.

\section{Análise dos dados}

Após a transcrição das entrevistas fez-se uma primeira leitura para adquirir uma visão geral do conteúdo obtido. Posteriormente, utilizando-se como embasamento os passos propostos por Minayo, foi realizada análise qualitativa dos dados ${ }^{(14)}$ :

$1^{\circ}$ ) Ordenação dos dados: reunir o material obtido durante o trabalho de coleta de dados, que inclui transcrição das fitas, releitura do material, organização dos relatos em ordem, ou seja, início de classificação; organização dos dados de observação (anotações realizadas durante ou após as entrevistas); 
$2^{\circ}$ ) Classificação dos dados: nessa fase inclui-se a leitura repetida e exaustiva do conteúdo transcrito das entrevistas (leitura flutuante), que permite apreender as idéias centrais que tentam transmitir e que ajudam a estabelecer as categorias empíricas do estudo;

$3^{\circ}$ ) Análise final: quando se articula o material teórico e o empírico (resultado da pesquisa); essa articulação está orientada pelo objetivo do estudo.

\section{RESULTADOS E DISCUSSÃO}

Dos 11 pacientes entrevistados, oito eram do sexo masculino e três do sexo feminino. A maioria deles, dez, era solteiro. A idade variou de 23 a 46 anos. Constatou-se que, antes do surgimento da doença, sete pacientes mantinhamse em atividade profissional definida, três eram responsáveis apenas por atividades domésticas e um só estudava.

Em relação ao grau de instrução, sete entrevistados não concluíram o ensino fundamental, um possuía ensino médio incompleto, dois concluíram o ensino médio e um possuía ensino superior incompleto. $\mathrm{O}$ tempo da doença variou de quatro a 28 anos e o número de internações antes do uso da clozapina, foi de duas a 15 vezes.

Quanto ao tempo de utilização da clozapina, obteve-se que, três pacientes faziam uso há sete anos, dois utilizavam há seis anos, dois há quatro anos, dois há três anos, uma paciente utilizava há dois anos e um era o primeiro paciente medicado com a clozapina no Brasil e fazia uso há 13 anos.

Em relação ao tempo de acompanhamento no grupo, verificou-se que cinco pacientes participavam há cinco anos, dois há quatro anos, dois há três anos e dois realizavam acompanhamento há dois anos. Apenas três pacientes reinternaram após o uso da clozapina e acompanhamento no grupo.

Quando questionou-se sobre vários aspectos do seu cotidiano, após participação no grupo e uso da clozapina, foi possível observar que os pacientes expressaram satisfação com o tratamento que vêm recebendo, o que está exemplificado nos temas que emergiram de seus depoimentos.

\section{Pacientes sentindo a melhora após a participação no grupo}

O grupo apresenta função psicopedagógica, no sentido de instruir o portador da doença, no que se refere às limitações, ajudando-o na adaptação social e contribuindo para conciliar sua situação de doença com as posturas de convivência requeridas pelo universo social ${ }^{(3)}$.

\footnotetext{
... depois do grupo, estou melhor... minha vida agora está boa... tem vez que um amigo da igreja fala prá mim vamos comigo na igreja?" Ele é evangélico e ele fala que eu preciso largar do remédio. Eu falo: "Não! Tem que tomar o remédio certinho, senão a mente fica fraca e eu posso ficar internado. (p.1)
}

Vários relatos de pacientes evidenciaram a valorização do grupo na contribuição da melhora progressiva de seus sintomas:

Melhorou de bater nos outros, melhorou de xingar as coisas de Deus, tá tudo feliz! Parou o nervoso, parou, para de bater nos outros e de tacar no chão. (p.3)

... melhorou mais! Controlou os pensamentos, mais melhor... tirei carta de moto, depois oficializei na música também. 0 grupo... a vida está mais melhor assim em vista do que eu tava. Quando eu tava assim... ouvindo as vozes. (p.6)

Há relatos que denotam a satisfação, envolvimento e compromisso dos pacientes em relação à participação no grupo.

\begin{abstract}
... só de saber que existe um grupo, que esse grupo é pra melhorar pessoa, pra pessoa tomar consciência, é isso ai! Eu não venho em busca de nada, não venho em busca que o doutor faça mágica, que vocês façam mágica não, vim como humano sabendo que eu tenho esse seguimento, essa responsabilidade... e essa responsabilidade é favorável pode me ajudar... pelo menos não fui internado nem mais uma vez. (p.9)
\end{abstract}

A terapia de grupo, com pacientes esquizofrênicos contribui de modo significativo para diminuição na frequiência de reinternações por proporcionar significativa melhora do teste de realidade, na redução do isolamento social, no aumento do compromisso com a medicação, nos aspectos volitivos e no aumento do senso de coesão ${ }^{(15)}$.

\section{Resgatando as relações com pessoas significativas}

A terapia de grupo apresenta-se voltada para o incentivo e desenvolvimento de habilidades sociais (atividades do cotidiano), especialmente no que se refere à diminuição do isolamento social ${ }^{(16)}$.

Legal, não é? Brinco com eles, com colegas, converso. (p.1)

Eu estou brincando com os meus irmãos, feliz, não estou batendo mais na minha mãe não! Estou feliz... (p.3)

... o relacionamento com a minha família é tudo bem não tem mais encrenca, não tem mais nada... (p.8)

... antes não ligava pra ninguém, não tinha nada de ficar escutando conselho... agora eles me acharam certinho, eu escondia muito só dava preocupação pra eles, só que agora eles me acharam... eu acho que eu entrei mais dentro, de primeiro eu era mais desligado, eu não me envolvia muito com as minhas sobrinhas não, quase nem conversava com elas, agora eu converso com elas... (p.9)

Hoje tudo bem! Tudo mundo no meu bairro gosta de mim, tenho bastante amigos. (p.10)

\section{A retomada das atividades domésticas e ocupação/ trabalho}

O nível de satisfação do paciente também pode ser atingido através da realização de atividades consideradas pequenas. Em determinadas atividades domésticas, o doente colabora da melhor maneira possível, transformando-a em uma atividade significativa ${ }^{(17)}$. 
... varro a casa, lavo os trem, lavo minhas calcinha, varro a casa, passo pano nos móveis, só de sábado... (p.3)

Eu varro lá a frente, lavo carro, capino lá no posto, saio um pouco para comprar cigarro para minha mãe, comprar mistura, vou no banco pagar conta para minha irmã, só que eu fico andando pra lá e pra cá. (p.5)

... melhorei, no serviço eu não fazia nada de primeiro, eu faço de tudo, eu limpo a casa, limpo o fogão, eu faço tudo, lavo os trens, fica limpinha a casa, dá gosto de entrar na minha casa. Eu cuido dos meus sobrinhos... estou ajudando minha avó. Ela está dando um dinheirinho pra mim, eu estou indo lá limpar a casa dela uma vez por semana. Aí, eu dou o dinheiro tudo pra minha mãe. (p.10)

... arrumo cozinha na hora do almoço e na hora do jantar. (p.11)

Alguns pacientes, após acompanhamento em grupo, apesar das dificuldades oriundas tanto da sintomatologia da doença como do mercado competitivo, conseguem vivenciar o trabalho remunerado em seu cotidiano.

... eu estou trabalhando, mas não consigo fazer tudo, entendeu? Eu faço alguma coisa, estou quase dois anos, já era pra ter aprendido pelo menos a metade... minha memória é fraca... tento fazer o que tiver na minha possibilidade... no grupo eu aprendi a pensar assim... (p.2)

... depois trabalhei um pouco de relojoeiro, também uns dois, três meses mais ou menos, depois ajudando dentro de casa assim... lavar louça, fazer alguma coisa assim. Hoje eu trabaIho de servente de pedreiro com meu tio e primos... (p.6)

... trabalho é ótimo, é ótimo, você não cansa, se consegue fazer as coisas... (p.8)

Apesar da importância do trabalho remunerado na reabilitação do paciente, constata-se que até $90 \%$ dos pacientes com problemas mentais graves se encontram desempregados. Uma investigação(18) aponta que após um ano de trabalho, $40 \%$ dos pacientes portadores de esquizofrenia que eram pagos por seus serviços alcançaram melhora em todos os sintomas e $50 \%$ informou muita melhora nos sintomas positivos. Para os que não recebiam por seu trabalho, a melhora foi consideravelmente menor. Menos de um quarto dos pacientes esquizofrênicos estão inseridos em programas que possibilitam encontrar um trabalho para se manter.

Apesar de dependerem de medicação, portadores de esquizofrenia, com quadros graves, conseguem melhorar até a ponto de poderem desempenhar o trabalho. Embora não se possa falar em cura, tal como a cura total preconizada pela medicina, a reabilitação psicossocial da maioria desses pacientes tem sido bastante evidente. Apesar de na esquizofrenia haver tendência a mais seqüelas a cada novo surto, o importante é saber que estas pessoas podem chegar a exercer funções na sociedade podendo, ainda, serem muito produtivas, dentro de suas possibilidades ${ }^{(19)}$.
Entretanto, em um país em que o desemprego é constante, sobram poucas ou nenhuma oportunidade para pessoas portadoras de doença mental. Suas chances nesse mercado competitivo são precárias, fazendo com que se confirme o sentimento de fracasso no sentido de integrar-se no mundo social.

\section{Manifestando interesse em retomar os estudos}

As falas abaixo, expressam a vontade dos sujeitos em retomar os estudos, fato este, não observado antes do acompanhamento em grupo. Alguns depoimentos, entretanto, revelaram que a vontade de retomar os estudos vem acompanhada pelas dificuldades do paciente em fazê-lo.

Acho que vou fazer psicologia no meio do ano, quero voltar estudar. (p.4)

... queria tanto ter uma profissão melhor, voltar estudar, é um sonho não é?... não consegui... mas acho que não tem jeito, sou louco para voltar, mas acho que não tem jeito, porque eu falo a verdade para você minha memória está fraca! (p.2)

... que nem ontem minha tia pegou os livros... para estudar em casa ela pegou dois da quarta série, um da quinta, outro da sexta... estava fazendo, não estava entendendo muito... tem que ir devagarzinho! (p.7)

\section{A satisfação demonstrada sobre a possibilidade de retomar e prosseguir os estudos}

Podemos constatar, através dos relatos abaixo, que grande parte dos pacientes, após iniciar acompanhamento em grupo conseguiu retomar e prosseguir com o estudo. Alguns expressaram, em seus relatos, satisfação em estudar e mencionaram bom desempenho escolar.

Hoje eu estudo, estou no terceiro... já estou se formando este ano. (p.1)

... voltei a estudar... no começo fiquei com medo de não dar conta, mas estou conseguindo... (p.9)

... voltei a estudar estou indo bem... mas é bom voltar estudar. Eu tenho muita vontade de ser alguma coisa na vida sabe. (p.10)

\section{As dificuldades encontradas no desenvolvimento educacional}

Parte dos pacientes mencionaram não ter retomado o estudo, apresentando como justificativa a falta de vontade de estudar, dificuldade em memorizar a matéria ministrada e outros referiram apenas não estarem estudando.

... escola não quero mais, eu não quero mais, não tenho vontade de voltar. (p.8)

Não voltei a estudar nunca mais. Não dá, não consigo guardar as contas... conta dos dois eu não consigo de jeito nenhum... (p.11)

\section{A participação em atividades de convívio social}

Os depoimentos dos pacientes sobre as atividades de lazer, antes do acompanhamento em grupo, revelaram que as mes- 
mas eram restritas e os pacientes preferiam ficar em casa. Quando questionados sobre a realização de atividades de lazer após acompanhamento em grupo os pacientes relataram várias, tais como, jogos (bola, ping-pong, fliperama, botiche), entre outros, como: ir a igreja, clubes, festas, assistir televisão, ouvir músicas, presentes nos relatos a seguir.

... faço computação, jogo bola na rua de casa. (p.1)

\begin{abstract}
"Meu lazer no clube, é jogar boticha. Em casa fico assistindo televisão, ouvir musica, jogando ping-pong, fliperama. (p.4)
\end{abstract}

... vou na igreja, toco instrumento lá, na orquestra de música... faço mais é ir na igreja, ficar em casa, as vezes viajar. (p.6)

\begin{abstract}
... bom vou lá no bar que é perto de minha casa, vou lá e tomo refrigerante um seis refrigerante por dia... jogo snoquer, não ganhava tanto estou ganhando agora, estou aprendendo a ganhar mais o jogo, lá é gostoso é um divertimento é uma delícia. (p.8)
\end{abstract}

As experiências de lazer contribuem significativamente para a valorização dos elementos do prazer, da liberdade, da afetividade, da emoção e da espontaneidade, cooperando para a promoção do desenvolvimento do homem de modo efetivo, atrelando-se, positivamente, a sua ação no mundo ${ }^{(20)}$.

\section{CONSIDERAÇÕES FINAIS}

A partir da década de 80, como o movimento de oposição ao manicômio e as práticas manicomiais, começaram a surgir novas experiências na prática assistencial, que vão ao encontro das novas propostas da Reforma Psiquiátrica Brasileira, com a qual busca-se preservar os direitos e a cidadania do indivíduo portador de sofrimento psíquico $^{(21)}$.

Dentro dessa visão, a problemática da psiquiatria não constitui mais a cura, a vida produtiva, mas a produção de vida voltada para a sociabilidade, utilização dos "espaços coletivos" e de "convivência dispersa"(17).

\section{REFERÊNCIAS}

1. Conley RR, Kelly DL. Tratamento farmacológico da esquizofrenia. Rio de Janeiro: Publicações Científicas; 2001.

2. Louzã Neto MR. Convivendo com a esquizofrenia: um guia para pacientes e familiares. São Paulo: Lemos; 1996.

3. Louzã Neto MR, Shirakawa I. O enfoque médico atual. In: Louzã Neto MR, Shirakawa I, Barros L. Esquizofrenia: dois enfoques complementares. São Paulo: Lemos; 1999. p. 13-44.

4. Taylor CM. Fundamentos de enfermagem psiquiátrica de Mereness. 13 ${ }^{\text {a }}$ ed. Porto Alegre: Artes Médicas; 1992.
Sabe-se que existem possibilidades diversas para atender o portador de esquizofrenia e seu familiar. Muitos pacientes esquizofrênicos que realizam, além do tratamento medicamentoso, alguma forma de terapia psicossocial, obtiveram êxito, principalmente quando envolvidos com outras famílias que compartilham dificuldades semelhantes ${ }^{(18)}$.

Algumas dessas pessoas, mesmo tomando a medicação regularmente, podem ter recaída dos sintomas psicóticos; além desse risco, o usuário de antipsicóticos atípicos, como a clozapina, tem o risco de agranulocitose, sendo necessária monitorização sanguínea periódica. Assim, é muito importante que, tanto o paciente quanto o familiar, saibam reconhecer os sintomas de recaídas e indicativos de alterações sanguíneas, pois a intervenção precoce da equipe de saúde pode impedir a recaída bem como controlar o quadro clínico do paciente.

Foi possível verificar com este estudo que o grupo em questão possibilitou aos pacientes serem orientados a reconhecer os sintomas, ou as situações estressantes que podem servir de disparadores para um novo surto esquizofrênico, bem como os sinais prévios de efeitos colaterais concernentes ao tratamento medicamentoso.

Constatou-se melhora do relacionamento, antes difícil, a diminuição da ansiedade e da agressividade, o aumento da auto-estima, da tolerância e força de vontade bem como o fortalecimento dos vínculos familiares.

Essa melhora no nível de recuperação contribuiu de modo significativo para a adesão ao tratamento e para mudança qualitativa nos tratamentos em si. Simultaneamente, houve o rompimento da solidão e do isolamento social, que a maioria dos pacientes se encontrava antes de freqüentar os grupos, recompondo o círculo de amizades e de convívio social, permitindo a concretização de um primeiro nível de ressocialização que a muitos conduz, seguida, do reinício de tentativas de reintegração social plena, evidenciadas pela busca do retorno aos estudos ou atividades profissionais ${ }^{(22)}$.

5. Bechelli PC, Caetano D. Clozapina um neuroléptico atípico: propriedades farmacológicas e uso terapêutico. J Bras Psiquiatr. 1992;41(1):45-135.

6. Silva CER, Pereira BB, Rozenthal M, Elkis H. Estudo-piloto com clozapina em hospital público: resultados de um ano de acompanhamento. Rev Bras Psiquiatr. 2001;23(4):180-7.

7. Chaves AC, Mari JJ, Shirakawa I. A clozapina é mais eficaz no tratamento da esquizofrenia do que os neurolépticos convencionais? Rev ABP-APAL. 1993;15(1):26-30. 
8. Zanini MH, Cabral RRF. Psicoterapia de grupo na esquizofrenia. In: Shirakawa I, Chaves AC, Mari JJ, editores. O desafio da esquizofrenia. São Paulo: Lemos; 2001. p. 165-82.

9. Yalom ID. The theory and pratice of group psychotherapy. New York: Basic Books; 1970.

10. Zimmerman DE, Osório LC. Como trabalhamos com grupos. Porto Alegre: Artes Médicas; 1997.

11. Ruiz VR, Lima AR, Machado AL. Educação em saúde para portadores de doença mental: relato de experiência. Rev Esc Enferm USP. 2004;38(2):160-6.

12. Polit DF, Hungler BP. Fundamentos de pesquisa de enfermagem. $3^{\mathrm{a}}$ ed. Porto Alegre: Artes Médicas; 1995.

13. Conselho Nacional de Saúde. Resolução n. 196, de 10 de outubro de 1996. Diretrizes e normas regulamentadoras de pesquisas envolvendo seres humanos. Bioética. 1996;4(2 Supl):15-25.

14. Minayo MCS. O desafio do conhecimento: pesquisa qualitativa em saúde. $4^{a}$ ed. São Paulo: Hucitec; 1996.

15. Shirakawa I, Nishikawa E, Cunha MJ. Grupo Operativo de Esquizofrênicos: uma experiência de três anos. Rev Assoc Bras Psiquiatr. 1982;4(13):46-9.
16. Kaplan HI, Sadock BJ. Compêndio de psiquiatria: ciências comportamentais, psiquiatria clínica. $6^{\mathrm{a}}$ ed. Porto Alegre: Artes Médicas; 1993.

17. Monteiro ARM, Barroso MGT. Trabalho x doença mental: percepção da família. Rev Bras Enferm. 1999;52(1):118-28.

18. Santos LC. Esquizofrenia [texto na Internet]. Niterói: Sociedade Psicanalítica Ortodoxa do Brasil; 2002. [citado 2002 maio 9]. Disponível em: http:www.spob.com.br

19. Ballone GJ. Psicoses-3: esquizofrenia orientação familiar [ texto na Internet]. [citado 2003 jun. 13]. São Paulo: UOL; 2003. Disponível em: http://gballone.sites.uol.com.br/psicori.htm1

20. Camargo RAA. Lazer, a vida além do trabalho para uma equipe de futebol entre trabalhadores de hospital [dissertação]. Ribeirão Preto: Escola de Enfermagem de Ribeirão Preto, Universidade de São Paulo; 2002.

21. Wetzel C. Trabalhando junto à família em um serviço comunitário de atenção á saúde mental. Cad IPUB. 2000;(19):203-9.

22. Barros L. O enfoque dos grupos de auto-ajuda. In: Louzã Neto ML, Shirakawa I, Barros L. Esquizofrenia: dois enfoques complementares. São Paulo: Lemos; 1999. 